\title{
Endoscopic ultrasound of pneumatosis cystoides intestinalis
}
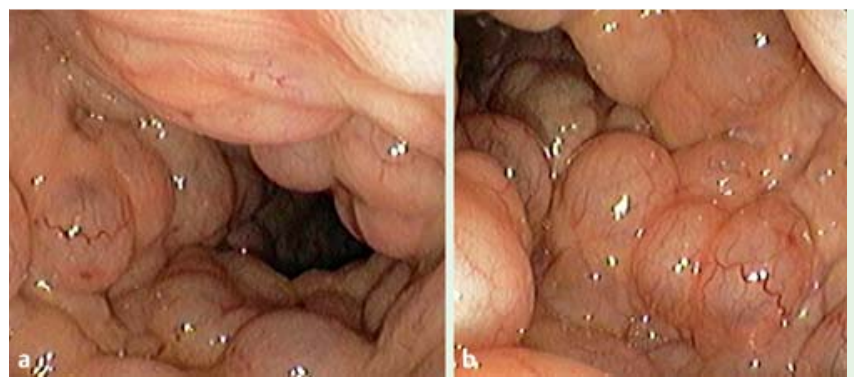

Fig. 1 Colonoscopic views in a 65-year-old asymptomatic man showing multiple bumps in the wall protruding into the lumen.

An asymptomatic 65-year-old man with an unremarkable medical history underwent colonoscopy for colon cancer screening. This showed multiple bumps in the bowel wall of variable size $(2-25 \mathrm{~mm})$ protruding into the lumen. These appeared to be interconnected and covered with normal-looking mucosa, with no areas of sparing in the sigmoid and proximal rectum ( $\bullet$ Fig. 1 ). No other lesions of the mucosa were observed. The patient's physical examination was normal and the results of routine laboratory analysis showed no abnormalities.

To clarify the diagnosis, endoscopic ultrasound (EUS) was performed with a $12-\mathrm{MHz}$ miniprobe that was advanced through the working channel of the colonoscope. This showed multiple hyperechoic air pockets (very echogenic with shadowing) in the submucosal layer, establishing the diagnosis of pneumatosis cystoides intestinalis (PCI) ( Fig.2). No further evaluation or management was needed.
$\mathrm{PCI}$ is a rare condition defined as the presence of air-filled cysts in the bowel wall. It occurs in two forms: primary, which is benign and usually asymptomatic, with normal mucosa; and secondary, which is generally due to chronic pulmonary disease or bowel ischemia.

There have been few reports of the use of EUS in the evaluation of bumps in the colon that are suggestive of PCI [1-4]. Colonoscopy and EUS performed with a miniprobe allow for the detailed characterization of bumps in the colonic wall and the diagnosis of $\mathrm{PCI}$ in a single procedure with no additional risks. Therefore, it is possible to establish a diagnosis and other diagnostic tests, such as computed tomography (CT) scanning, do not need to be performed. This approach can also avoid the inadvertent and dangerous endoscopic resection of such lesions.

\section{Endoscopy_UCTN_Code_CCL_1AF_2AH}

\section{Competing interests: None}

\section{Fernando Castro-Poças ${ }^{1,2}$, Tarcísio Araújo ${ }^{1}$, Isabel Pedroto ${ }^{1,2}$}

${ }^{1}$ Department of Ultrasound and Department of Gastroenterology, Santo António Hospital, Porto Hospital Center, Porto, Portugal

${ }^{2}$ Institute of Biomedical Sciences Abel Salazar, University of Porto, Portugal

\section{References}

1 Abu-Hamda E, Erickson R. Bumps in the colon: utility of EUS for colonic submucosal masses. Visible Hum J Endosc 2003; 2: 2-6

2 Bamakhrama K, Abdulhady L, Vilmann P. Endoscopic ultrasound diagnosis of pneumatosis cystoides coli initially misdiagnosed as colonic polyps. Endoscopy 2014; 46 (Suppl. 01): E195-E196

3 Pontes J, Catré A. Diagnosis of pneumatosis cystoides intestinalis by endoscopic ultrasound [Abstract]. Gastrointest Endosc 2000; 51: AB286

4 Chang Y, Chang M, Wei S et al. Pneumatosis cystoides coli. Gastrointest Endosc 2006; 64: $820-821$

\section{Bibliography}

Dol http://dx.doi.org/

10.1055/s-0034-1391873

Endoscopy 2015; 47: E274

(C) Georg Thieme Verlag KG

Stuttgart · New York

ISSN 0013-726X

\section{Corresponding author}

\section{Fernando Castro-Poças, MD}

Department of Gastroenterology

Santo António Hospital

Largo Prof. Abel Salazar

4099-001 Porto

Portugal

Fax: +351-22-2053218

castro.pocas@sapo.pt
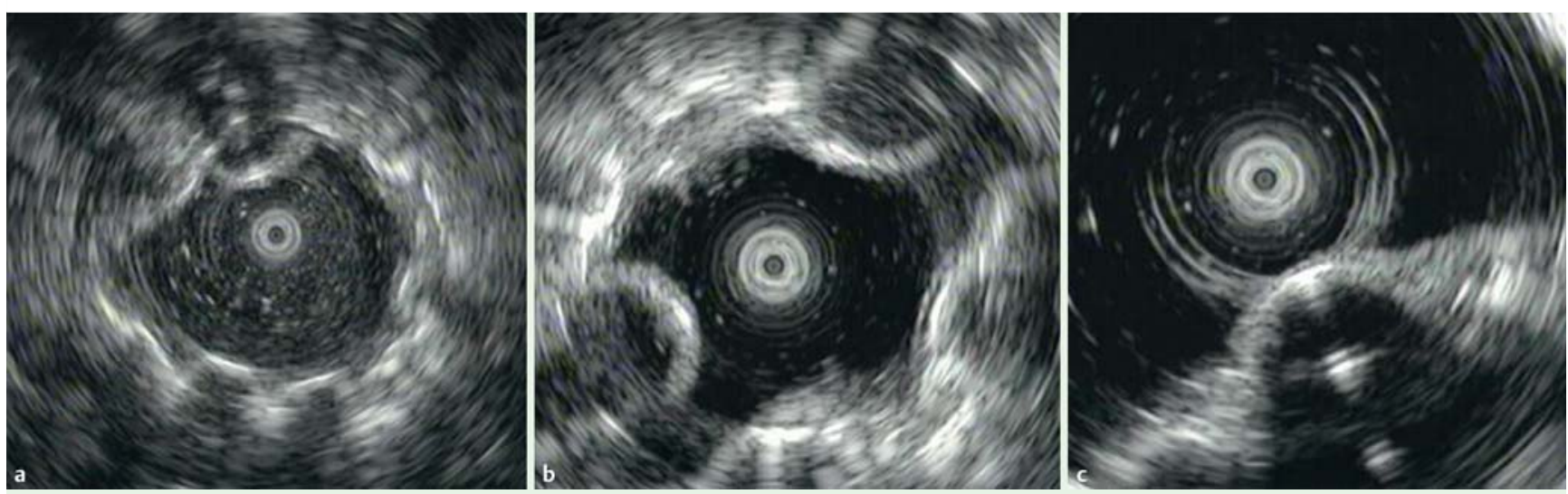

Fig.2 Endoscopic ultrasound (EUS) views showing multiple hyperechoic air pockets in the submucosa of the colonic wall, consistent with pneumatosis cystoides intestinalis. 